\title{
A study of the histological cell types of lung cancer in workers suffering from asbestosis in the United Kingdom
}

\author{
F. WHITWELL, MURIEL L. NEWHOUSE', AND DIANE R. BENNETT \\ TUC Centenary Institute of Occupational Health, London School of Hygiene and Tropical \\ Medicine, Keppel Street, London WC1E 7HT
}

\begin{abstract}
Whitwell, F., Newhouse, Muriel, L., and Bennett, Diane R. (1974). British Journal of Industrial Medicine, 31, 298-303. A study of the histological cell types of lung cancer in workers suffering from asbestosis in the United Kingdom. The present study concerns the predominant cell type of lung cancer in workers with certified asbestosis who died of carcinoma of the lung in the United Kingdom between 1962 and 1972. Clinical data, necropsy reports, histological sections, and in some cases paraffin blocks were obtained from the nine pneumoconiosis panels in the country and from hospitals where the patients had been treated. Histological analysis was confined to the 88 male and nine female cases in which adequate postmortem tissue had been obtained. The number of female cases was considered to be too small to be of value as a separate series. Among the males, adenocarcinoma was the commonest type of lung cancer found in $34 \%$. Information about the smoking habits of 69 of the 88 men was obtained; all had smoked at some time. There was little difference between the smoking habits of any group whatever the cell type of carcinoma. The difficulty in finding a comparable series of nonasbestos-exposed individuals is pointed out. It is the usual practice to hold a necropsy on any patient when asbestosis has been certified wherever the place of death. This series therefore has a wider basis of selection than any hospital-based series.

Cigarette smoking can exert a carcinogenic effect on different parts of the bronchial tree, producing squamous or oat-celled tumours proximally and adenocarcinoma distally. Asbestos dust lying in distal parts of the lung may exert a co-carcinogenic probably a multiplicative effect with tobacco smoke, producing adenocarcinoma of the distal part of the respiratory tract.
\end{abstract}

Lung cancer occurs much more commonly in asbestos workers than in comparable populations who have had no asbestos exposure (Doll, 1955; Selikoff, Churg, and Hammond, 1964; Jacob and Anspach, 1965; Newhouse, 1969; Newhouse, Berry, Wagner, and Turok, 1972). However, Selikoff, Churg, and Hammond (1968) have shown that lung cancer is rarely found in non-smoking asbestos workers, and recent evidence (Berry, Newhouse, and Turok, 1972) suggests that asbestos and cigarette

${ }^{1}$ Requests for reprints to Dr. M. L. Newhouse. smoke have a multiplicative carcinogenic effect. In the United Kingdom lung cancer is not itself a prescribed disease in asbestos workers, the granting of industrial compensation being dependent upon the presence of asbestosis.

There have been very few studies of the cell-type frequencies of lung cancer in those with asbestosis, most accounts being based upon very small series. Hueper (1966) collected published cases and found an unusually high percentage of adenocarcinoma. Hourihane and McCaughey (1966) examined 17 cases and found that adenocarcinoma occurred with 
unexpected frequency. Spencer (1968) states that asbestos cancers tend to be of the peripheral adenocarcinoma variety. On the other hand, Kreyberg (1968) considers that lung cancers caused by environmental factors such as tobacco smoke or asbestos dust tend to be squamous or oat-cell carcinomas, and recently Kannerstein and Churg (1972) have found no difference in the cell-type frequency in a series of lung cancers in asbestos workers compared with lung cancers in non-asbestos-exposed individuals in whom the cancer was presumably cigaretteinduced.

This conflict of opinion as to the predominant cell type of lung cancer associated with asbestosis has stimulated the present study, which has been concerned with assessing the significance of the celltype frequency found in a large series of workers suffering from asbestosis who died of lung cancer.

\section{Present investigation}

In the United Kingdom workers suspected of having asbestosis are referred to pneumoconiosis medical panels which are situated in London, the major industrial centres in England and Wales, and in Glasgow in Scotland. The worker is examined clinically and radiologically and his pulmonary function is evaluated. If the panel confirms the diagnosis, he is certified as suffering from asbestosis and becomes eligible for compensation. $\mathrm{He}$ is re-examined and reassessed annually and at death is the subject of necropsy followed by a coroner's inquest. It is the usual practice for panels to preserve all clinical records of these patients together with radiographs and necropsy reports, and often histological slides from surgical or necropsy specimens.

In the present investigation we were fortunate in having access to lists, compiled by the then Medical Division of the Department of Employment (now the Employment Medical Advisory Service) of all deaths from lung cancer occurring in those suffering from asbestosis as certified by the pneumoconiosis panels between 1962 and 1970 . We circulated these lists to the various panels with requests for the loan of clinical notes, necropsy reports, and any histological slides.

The total material of this study consists of the cases received from the pneumoconiosis medical panels occurring between 1962 and 1970, additional cases from Scotland from 1970 until the end of 1972, and a further 23 patients who had worked at a London East End asbestos factory and had died of lung cancer, all but three of whom suffered from certified asbestosis (Newhouse, 1969). The clinical notes were abstracted, and where necessary further information about past occupations, smoking habits, bronchoscopy, radiographs, and histopathology were sought from the hospital where the patients had been treated.

\section{Pathological material}

The material consisted of histological sections and sometimes paraffin blocks of tissue which had been prepared mainly from postmortem examinations but occasionally from bronchial biopsies, and lobectomy and pneumo- nectomy specimens. In some postmortem cases there had been previous surgical removal of the tumours and histological sections of these were also available.

Sections were stained only with haematoxylin and eosin but sometimes tissues had been stained with van Gieson, Perls', and mucin stains.

\section{Classification of tumours}

The histological classification of lung tumours used was a simplified form of the World Health Organisation classification and has been used previously in a survey of lung cancer in Liverpool (Whitwell 1961a, b). In this classification squamous tumours are so called only if tumour cells are seen to be forming keratin or forming prickle cells; adenocarcinomas reveal acinar structure and/or mucin secretion. A case of malignant pulmonary adenomatosis or alveolar-cell carcinoma was grouped with the adenocarcinomas. Oat-cell carcinomas all showed the characteristic small oval nuclei in eosinophilic cytoplasm, which rarely showed cell margins, and these tumours sometimes showed acinar formation. Carcinomas with none of these features were classified as carcinoma simplex, in which group also were included giant-cell and clear-cell carcinomas. Tumours showing a mixed cellular pattern were grouped together as such and were mainly adenosquamous carcinomas.

Where a tumour was largely undifferentiated but contained some differentiated areas it was grouped according to the differentiated tissue.

\section{Grading of asbestosis}

It has been assumed that at postmortem examinations the lung tissues selected for microscopic examination had been taken from the most severely affected areas.

The lung tissues have been graded as follows:

1. Normal: Asbestos bodies were usually present in small or moderate numbers but were within the bronchioles and distal air-spaces with no interstitial fibrosis.

2. Mild asbestosis: A similar number of asbestos bodies was present but many of these were in the interstitial tissues of the lung where there was slight, often focal, interstitial fibrosis with some irregular emphysema.

3. Moderate asbestosis: Usually more asbestos bodies were present and the lung tissue showed extensive interstitial fibrosis with obliteration of alveoli, cystic dilatation of bronchioles with epithelial hyperplasia, irregular emphysema, and collagenous pleural thickening.

4. Severe asbestosis: The numbers of asbestos bodies present were variable, being usually numerous. Fibrosis was advanced to a degree where it was difficult to recognize the tissue as lung. There was frequent cystic dilatation of bronchioles with adenomatous and squamous metaplasia. Irregular emphysema and pleural collagenization were usually present.

\section{Results}

Of the 197 patients listed, clinical and pathological material was obtained in 145 cases $(66 \%)$. The 
TABLE 1

Preliminary ANalysis of Specimens

\begin{tabular}{l|c|c|c}
\hline & Male & Female & Total \\
\hline Inadequate material & 23 & 2 & 25 \\
Mesothelioma or other tumour & 10 & 1 & 11 \\
Operation tissue only & 11 & 1 & 12 \\
Satisfactory postmortem tissues & 88 & 9 & 97 \\
\hline Total cases examined & 132 & 13 & 145 \\
\hline
\end{tabular}

results of the preliminary sorting are shown in Table 1.

In the cases grouped as inadequate there was insufficient tumour tissue in the sections obtained at biopsy or operation or from subsequent necropsy to be able to consider it representative of the main tumour.

There were 11 cases where the appearances were not those of a primary lung cancer, seven of them probably being mesotheliomas and the others secondary carcinomas.

For these reasons the histological analysis has been confined to the 97 cases where there was adequate postmortem tumour tissue and, except in two cases, adequate lung tissue. The number of female cases is too small to be of value as a separate series, and as the histological cell-type frequency in women may differ from that found in men the female cases have been listed separately to avoid one factor which confuses cell-type frequency studies. This has left

TABLE 2

Histological Type of Tumour

\begin{tabular}{l|rr|r|r}
\hline & Male & $\%$ & Female & Total \\
\hline Squamous & 19 & $21 \cdot 6$ & 2 & 21 \\
Oat & 23 & $26 \cdot 1$ & 3 & 26 \\
Adenocarcinoma & 30 & $34 \cdot 1$ & 3 & 33 \\
Simplex & 12 & $13 \cdot 6$ & 1 & 13 \\
Mixed & 4 & $4 \cdot 6$ & - & 4 \\
\hline Total & 88 & & 9 & 97 \\
\hline
\end{tabular}

TABLE 3

Histological TYPE OF TUMOUR IN 86 Lungs Graded by Severity of Asbestosis

\begin{tabular}{l|cc|cc}
\hline \multicolumn{1}{c|}{ Cell type } & \multicolumn{2}{c|}{$\begin{array}{c}\text { Normal lung and } \\
\text { mild asbestosis }\end{array}$} & \multicolumn{2}{c}{$\begin{array}{c}\text { Moderate and } \\
\text { severe asbestosis }\end{array}$} \\
\cline { 2 - 3 } & No. & $\%$ & No. & $\%$ \\
\hline Squamous & 8 & $28 \cdot 6$ & 11 & $19 \cdot 0$ \\
Oat & 7 & $25 \cdot 0$ & 16 & $27 \cdot 6$ \\
Adenocarcinoma & 7 & $25 \cdot 0$ & 22 & $37 \cdot 9$ \\
Other & 6 & $21 \cdot 4$ & 9 & $15 \cdot 2$ \\
& & & & \\
\hline
\end{tabular}

88 male asbestos lung cancers for analysis. The histological typing of the tumours is shown in Table 2 with the percentage distribution of the male cases. Adenocarcinoma was the commonest type of lung cancer, found in $34 \%$ of cases.

If asbestosis has any influence on the cell-type frequency in the series it is likely that this would be shown by comparing the cell-type frequency in the less severe cases of asbestosis with the more severely affected. In Table 3 the cell-type frequency of the cases with normal and mild asbestosis is compared with that found in those with moderate and severe asbestosis. Two cases have been omitted where there was inadequate lung tissue to classify by the type of asbestosis. The table shows that in normal and mild asbestosis $25 \%$ of the tumours were adenocarcinoma, whereas in the more severe asbestosis $38 \%$ of the tumours were adenocarcinoma. However, this difference was not statistically significant.

\section{Site of tumour}

An attempt was made to assess whether the tumour arose in the upper or lower lobes and centrally or peripherally, using necropsy reports together with reports of straight radiographs, tomography, bronchoscopy, and surgery. In 65 of the series there was a clear indication of the lobe of origin; $19(63 \%)$ of the 30 tumours classified as adenocarcinoma and 32 $(55 \%)$ of the other cell types of the tumour appeared to originate in one or other lower lobe. In 75 of the male series it was possible to make a judgment whether the tumour was central or peripheral in origin. Of the adenocarcinomas, $15(50 \%)$ were described as peripheral compared to $16(27 \%)$ of the tumours of other histological types.

\section{Other features of the series}

During the examination of pneumoconiosis panel notes and hospital records the opportunity was taken to note smoking habits and certain other aspects of the disease.

TABLE 4

Smoking Habit by Cell Type

\begin{tabular}{l|ccc|c}
\hline Smoking habit & $\begin{array}{c}\text { Squamous and } \\
\text { oat-cell }\end{array}$ & $\begin{array}{c}\text { Adeno- } \\
\text { carcinoma }\end{array}$ & Other & Total \\
\cline { 2 - 5 } Non-smoker & 0 & 0 & 0 & 0 \\
Ex-smoker & 6 & 3 & 2 & 11 \\
$\begin{array}{c}\text { < 10 cigarettes } \\
\text { 10-20 cigarettes }\end{array}$ & 8 & 5 & 1 & 14 \\
20+ cigarettes & 12 & 7 & 7 & 26 \\
$\begin{array}{c}\text { Smoking habit } \\
\text { known }\end{array}$ & 8 & 7 & 3 & 18 \\
\cline { 2 - 5 } $\begin{array}{c}\text { Smoking habit } \\
\text { not known }\end{array}$ & 34 & 22 & 13 & 69 \\
\hline
\end{tabular}


TABLE 5

Some features of Patients with Tumours of Different Cell Types

\begin{tabular}{|c|c|c|c|c|c|c|c|c|}
\hline \multirow[t]{2}{*}{ Cell type } & \multicolumn{2}{|c|}{ Age at first exposure } & \multicolumn{2}{|c|}{ Age at death } & \multicolumn{2}{|c|}{ Latent period } & \multicolumn{2}{|c|}{ Length of exposure } \\
\hline & No. & Mean & No. & Mean & No. & Mean & No. & Mean \\
\hline $\begin{array}{l}\text { Squamous } \\
\text { Oat-cell } \\
\text { Adenocarcinoma } \\
\text { Other }\end{array}$ & $\begin{array}{l}17 \\
21 \\
27 \\
14\end{array}$ & $\begin{array}{l}28 \cdot 1 \\
29 \cdot 6 \\
30 \cdot 8 \\
28 \cdot 3\end{array}$ & $\begin{array}{l}19 \\
23 \\
30 \\
16\end{array}$ & $\begin{array}{l}62 \cdot 7 \\
57 \cdot 6 \\
59 \cdot 8 \\
56 \cdot 3\end{array}$ & $\begin{array}{l}17 \\
21 \\
27 \\
14\end{array}$ & $\begin{array}{l}33 \cdot 6 \\
29 \cdot 3 \\
28 \cdot 7 \\
27 \cdot 9\end{array}$ & $\begin{array}{l}18 \\
23 \\
29 \\
14\end{array}$ & $\begin{array}{l}18 \cdot 9 \\
21 \cdot 2 \\
21 \cdot 9 \\
22 \cdot 9\end{array}$ \\
\hline
\end{tabular}

Smoking habits The smoking habits of 69 of the 88 men in the series had been recorded (Table 4). All the men had smoked cigarettes, though three had given up the habit over 20 years before death and eight others had given up more recently.

Though the numbers are small they do not suggest that the heavier cigarette smokers were liable to any particular cell-type of lung cancer. Sixty-seven per cent of the patients with squamous and oat-cell carcinomas were moderate or heavy smokers, while the corresponding figures for those with adenocarcinomas and for the other cancers were $64 \%$ and $76 \%$.

Age at first exposure In the different groups the mean age at first exposure varied only between 28 and 31 years. A quarter of the men in the series had started to work with asbestos between the ages of 14 and 18 , but nearly one-fifth had not been exposed until over the age of $\mathbf{4 0}$ (Table 5).

Age at death This was known for all patients, and the mean age at death for the different cell-types is also shown in Table 5. The figures are very similar to those found in cases of non-asbestos lung cancer; patients with oat-cell carcinoma usually die about five years younger than those with squamous carcinoma.

Latent period This has been calculated as the mean number of years between first exposure and death, and in the different groups varied between $27 \cdot 3$ and $33 \cdot 2$ years (Table 5).

Duration of exposure Apart from three men with squamous-cell tumours whose period of exposure was recorded as less than two years, all had been exposed for more than 10 years. The mean duration of exposure varied between $17 \cdot 8$ years for those with squamous-cell carcinoma to 21.9 years for those with adenocarcinoma. The difference was not statistically significant.

\section{Discussion}

This series, unlike most postmortem studies of the disease, is fully representative of lung cancer in those with certified asbestosis as it is the usual practice for coroners in England and the pneumoconiosis panels in Scotland to arrange a necropsy, and this applies whether the patients die in hospital or in their homes. The series clearly does not contain all subjects having certified asbestosis and lung cancer who died in the United Kingdom in the period surveyed, but those not included must have been omitted only because of administrative errors in not notifying cases to the authorities at death, not holding necropsies, losing records, or because pathologists took inadequate histological sections. None of these errors is likely to have occurred more often with any particular cell-type of tumour.

We consider that 88 cases form a large enough series to provide a reasonable assessment of the carcinoma cell-type frequencies occurring in certified asbestosis. Many patients with certified asbestosis have severe lung disease and it may be that lung cancers in early and slight cases of asbestosis are not adequately represented, so any carcinoma cell-type relationship with asbestosis is likely to be exaggerated in this series.

The real difficulty lies in finding a comparable series of non-asbestos but presumably cigaretteinduced lung cancers for comparison, and this seems to be insuperable. Most reported large series of lung cancers contain a high proportion of cases where the histological diagnosis is based upon bronchial biopsy specimens, so that they reflect the high incidence of squamous and oat-cell tumours in the larger accessible bronchi but ignore the more inaccessible peripheral adenocarcinomas. This can be seen in the papers by Wynder and Graham (1950) and by Doll and Hill (1964) referred to later. On the other hand, series based upon surgically resected specimens include a high proportion of squamous tumours, because they are more likely to be resectable, and a low proportion of oat-cell carcinomas and adenocarcinomas because these are more often found to be inoperable. All postmortem series from acute hospitals are influenced by the facts that patients with known inoperable cancer tend to be discharged home or to a chronic sick hospital, and hospital necropsies are often held only when the clinical 
TABLE 6

Cell Types in Male lung Cancer, Broadgreen Hospital, Liverpool, 1950-60, in Three Series

\begin{tabular}{|c|c|c|c|c|c|c|c|c|c|c|}
\hline \multicolumn{5}{|c|}{ Cell type } & \multicolumn{2}{|c|}{ Bronchial biopsy series } & \multicolumn{2}{|c|}{ Operation specimen series 1} & \multicolumn{2}{|c|}{ Necropsy series } \\
\hline $\begin{array}{l}\text { Squamous } \\
\text { Oat-cell } \\
\text { Adenocarcinom } \\
\text { Simplex } \\
\text { Other .. } \\
\end{array}$ & $\begin{array}{c}\cdots \\
\ddot{m a} \\
\cdots \\
\cdots\end{array}$ & $\begin{array}{l}\cdots \\
\cdots \\
\cdots \\
\cdots\end{array}$ & $\begin{array}{l}\cdots \\
\cdots \\
\cdots \\
\cdots\end{array}$ & $\begin{array}{l}\cdots \\
\cdots \\
\cdots \\
\cdots\end{array}$ & $\begin{array}{r}379 \\
311 \\
18 \\
167 \\
48\end{array}$ & $\begin{array}{r}41 \cdot 1 \\
33 \cdot 7 \\
2 \cdot 0 \\
18 \cdot 1 \\
5 \cdot 2\end{array}$ & $\begin{array}{r}465 \\
107 \\
77 \\
142 \\
24\end{array}$ & $\begin{array}{r}57 \cdot 1 \\
13 \cdot 1 \\
9 \cdot 4 \\
17 \cdot 4 \\
29\end{array}$ & $\begin{array}{r}17 \\
38 \\
29 \\
12 \\
7\end{array}$ & $\begin{array}{r}16 \cdot 5 \\
36 \cdot 9 \\
27 \cdot 2 \\
11 \cdot 6 \\
6 \cdot 8\end{array}$ \\
\hline Total & . & . & . & . & 923 & & 815 & & 103 & \\
\hline
\end{tabular}

${ }^{1}$ When operations followed bronchial biopsy the case is included only in the operation series.

diagnosis is uncertain. For these reasons a lung cancer necropsy series includes few of the more easily diagnosable proximal bronchial tumours such as squamous carcinomas, but it contains a high proportion of adenocarcinomas, which are less easily diagnosed and often present first with symptoms from their metastases.

These points are demonstrated in Table6, which has been prepared after removal of female cases from material already published (Whitwell, 1961b) on cases occurring in the Liverpool area in one hospital. The table shows the frequency of adenocarcinoma in the biopsy series to be $2 \%$, in the operation series $9.5 \%$, and in the postmortem series $28 \%$. These cases were probably mainly cigarette-induced carcinomas and in none was asbestosis found, but Liverpool is an area where $10 \%$ of adult males show pleural plaques at necropsy, and where pleural mesotheliomas are relatively common (Whitwell and Rawcliffe, 1971), so it is probable that if these Liverpool cases are used as a control series they may well underestimate differences between asbestos-exposed and non-asbestos-exposed populations. There is no true indication of the overall frequency of adenocarcinoma in an unselected population but probably the figure lies between 15 and $20 \%$, which is about half the frequency we have found in more severe asbestosis.

Comparison of the present asbestos cancer series with the earlier Liverpool series has the advantage that the same diagnostic criteria and classification have been used, and interpretation has been by the same pathologist.

Our finding of an overall frequency of $34 \%$ of adenocarcinomas in the lung cancer of certified asbestosis, and of $38 \%$ in the severely affected lungs (Table 3) is higher than in most series that have been published. Hueper (1966) found $19 \%$ of adenocarcinomas among 104 published cases and compared this with $9.5 \%$ in male controls. Hourihane and McCaughey (1966) found six adenocarcinomas among 17 male asbestos carcinomas, or about $35 \%$. On the other hand, Kannerstein and Churg (1972), in a study of 50 lung cancers in asbestos workers, found a frequency of $22 \%$, which was very similar to their control series. However, their series was a mixture of cases diagnosed by bronchial biopsy, secondary deposit biopsy, operation specimens, and postmortem tissues, and it is difficult to assess the significance of findings based upon such variable material.

Our study has emphasized the important factor of cigarette smoking in the development of asbestos lung cancer, supporting the views of Selikoff et al (1968). Retrospective studies rely upon clinical notes made long ago in case-records, and though routine notes concerning smoking habits can be misleading they usually tend to underestimate the smoking habits of patients. In the present series there were no patients who had not smoked cigarettes at some time, and $64 \%$ had been moderate or heavy smokers all their lives. There was no significant difference in the smoking habits of patients with different celltypes of lung cancer.

It is widely held that squamous and oat-cell carcinomas of the lung are the types caused by cigarette smoking, while adenocarcinomas are unrelated to this habit, an opinion largely derived from the studies of Wynder and Graham (1950), Doll and Hill (1954), and Kreyberg (1962, 1968). Among Wynder and Grahams' series of 644 male carcinomas there were only 39 adenocarcinomas, and the authors considered that they had not seen a sufficient number of adenocarcinomas to decide whether they contained a higher proportion of chain-smokers than was seen in the control patients. Doll and Hill found 33 adenocarcinomas in their series of 916 lung cancers and there was no statistical difference in the amounts smoked by patients with tumours of different histological groups, but they thought that the number of adenocarcinomas was too small to conclude that no difference existed. In 1964 these authors 
reported a prospective study of lung cancer in British doctors, from which they concluded that there was no marked association of smoking with adenocarcinomas, but this series included only 13 adenocarcinomas. Kreyberg $(1962 ; 1968)$ considers that lung cancers due to external carcinogens such as cigarette smoke and asbestos dust are mainly squamous and oat-cell tumours, and that adenocarcinomas are endogenous growths which have not risen greatly in their frequency in this century. His opinion is partly based upon re-examination and reclassification of material already studied by Doll and Hill, but in his later work (Kreyberg, 1968) he admits a threefold increase in the incidence of adenocarcinoma in cigarette smokers compared with nonsmokers.

The opposite view has been given by Ashley and Davies (1967) in a study of lung cancer in men from south Wales. Among 442 cases for which smoking histories were available there were 50 adenocarcinomas, and cigarette smoking was found to be associated with adenocarcinoma as often as with other types of lung cancer. They concluded that the histological type of tumour depended entirely upon which part of the respiratory tract was affected.

It is probable that cigarette smoking can exert a carcinogenic effect upon different parts of the bronchial tree, usually producing squamous or oatcell tumours when the more proximal areas are affected, and adenocarcinomas when distal parts are involved. As the concentration of carcinogen is likely to be higher in the more proximal parts of the bronchial tree it is to be expected that squamous and oat-cell tumours will be most common with cigarette-induced carcinoma. However, when asbestos dust, which reaches the distal parts of the bronchial tree, acts as a co-carcinogen with cigarette smoke, it is not surprising to find that the maximum carcinogenic effect, probably a multiplicative one, produces adenocarcinoma in the distal part of the respiratory tract.

We wish to thank Dr. Watkins Pitchford, Dr. R. M. McGowan, the doctors of the pneumoconiosis panels, and Dr. W. Buchanan of the Department of Employment for their assistance and co-operation, and Dr. J. G. Gilson and Professor R. S. F. Schilling for their interest and advice.

\section{References}

Ashley, D. J. and Davies, H. D. (1967). Cancer of the lung histology and biological behaviour. Cancer, 20, 165-174.
Berry, G., Newhouse, M. L., and Turok, M. (1972). Combined effect of asbestos exposure and smoking on mortality from lung cancer in factory workers. Lancet, 2, 476-479.

Doll, R. (1955). Mortality from lung cancer in asbestos workers. British Journal of Industrial Medicine, 12, 81-86.

- and Hill, A. B. (1954). Mortality of doctors in relation to their smoking habits. British Medical Journal, 1, 1451-1455.

_ and (1964). Mortality in relation to smoking: ten years' observations of British doctors. British Medical Journal, 1, 1399-1410, 1460-1467.

Hourihane, D. O'B. and McCaughey, W. T. E. (1966). Pathological aspects of asbestosis. Postgraduate Medical Journal, 42, 613-622.

Hueper, W. C. (1966). Occupational and environmental cancer of the respiratory tract. Recent Results in Cancer Research, vol. 3, p. 43. Springer, Berlin.

Jacob, G. and Anspach, M. (1965). Pulmonary neoplasia among Dresden asbestos workers. Annals of the New York Academy of Sciences, 132, 536-548.

Kannerstein, M. and Churg, J. (1972). Pathology of carcinoma of the lung associated with asbestos exposure. Cancer, 30, 14-21.

Kreyberg, L. (1962). Histological lung cancer types. A morphological and biological correlation. Acta Pathologica et Microbiologica Scandinavica, Supplement, no. 157.

- (1968). Non smokers and the geographic pathology of the lung. In The Lung, edited by A. A. Liebow and D. E. Smith, p. 273. Williams and Wilkins, Baltimore.

Newhouse, M. L. (1969). A study of mortality of workers in an asbestos factory. British Journal of Industrial Medicine, 26, 294-301.

—, Berry, G., Wagner, J. C., and Turok, M. E. (1972). A study of the mortality of female asbestos workers. British Journal of Industrial Medicine, 29, 134-141.

Selikoff, I. J., Churg, J., and Hammond, E. C. (1964). Asbestos exposure and neoplasia. Journal of the American Medical Association, 188, 22-26.

,-- , and - (1968). Asbestos exposure, smoking, and neoplasia. Journal of the American Medical Association, 204, 106-112.

Spencer, H. (1968). Pathology of the Lung, 2nd ed, p. 788. Pergamon Press, Oxford.

Whitwell, F. (1961a). Histopathology of lung cancer in Liverpool. A survey of bronchial biopsy histology. British Journal of Cancer, 15, 429-439.

- (1961b). Histopathology of lung cancer in Liverpool. The specificity of the histological cell types of lung cancer. British Journal of Cancer, 15, 440-459.

—, and Rawcliffe, R. M. (1971). Diffuse malignant pleural mesothelioma and asbestos exposure. Thorax, 26, 6-22.

Wynder, E. L., and Graham, E. A. (1950). Tobacco smoking as possible etiologic factor in bronchiogenic carcinoma. Journal of the American Medical Association, 143, 329-336. 
reliability. Since production is a man-machine system, a factor is designated as 'human confidence' which is considered as synonymous with safety. This is a useful concept, particularly as it enlarges the amount of data upon which the safety investigator may work, to include work factors other than those directly concerned with accidents. It is valid however only if more accidents occur as system reliability decreases, and the authors give limited evidence of this. In relation to the theoretical development the reader may feel that the treatment of accident prevention is rather inadequate.

The test of this type of concept, however, is whether it is fruitful in promoting progress, and anyone seriously nterested in safety who is equipped with appropriate technological assistance should study this document.

There are many concepts of value to be found, for example, the categorizing of activities into production, prevention, and recovery phases; and the observation that recovery activities are associated with at least three times more accidents than other parts of the work cycle.

Examples are given of worker involvement in defining and implementing safe practices of work, and these are advanced as the most effective means of obtaining success.

In the discussion on reliability and experience, an important point for training methods is made, namely that operators learn by the diagnosis of malfunctions, and the larger the number of different situations that are encountered, the more effective is the experience acquired. This re-emphasizes the trial and error concept of learning and is related to problems of automation, process, and control.

This book will be heavy going for anyone but an ergonomist or specialist in process control, and its mathematical bias although essential may deter many. The lack of a concluding chapter gathering together the salient points is a serious omission.

For the industrial physician this work is of general interest but not essential reading, except for those with a direct responsibility for safety or ergonomics who are prepared to devote some time to the mathematics. To these it offers considerable possibilities of advancing their practice.

J. W. HILL

\section{NOTICES}

\section{American Academy of Clinical Toxicology}

The American Academy of Clinical Toxicology will convene its 1975 annual meeting 8-10 August 1975 at the Crown Center, Kansas City, Missouri. Further information may be obtained from Dr. Walter J. Decker, Lt. Col., MSC, US Army Medical Laboratory, Fort Sam Houston, San Antonio, Texas 78234.

\section{International Congress on Occupational Health}

The XVIII International Congress on Occupational Health will be held at the Hotel Metropole, Brighton, England from 14-19 September 1975. For all information relating to the Congress please write to: XVIII International Congress on Occupational Health, Conference Services Limited, 43 Charles Street, Mayfair, London W1X 7PB.

\section{Institute of Sound and Vibration Research}

A further course on Industrial Audiology and Hearing Conservation is being organized within the Institute of Sound and Vibration Research 23 to 26 September 1975. The course will be particularly suitable for industrial medical officers, occupational hygienists, senior occupational health nurses and others involved in audio-metry and hearing conservation programmes.

Further information may be obtained from: Mrs. O. G. Hyde, ISVR Conference Secretary, The University Southampton, SO9 $5 \mathrm{NH}$.

\section{OMISSION}

On page 298 of the October 1974 issue of the journal Dr. F. Whitwell's address was not given. This is Broadgreen Hospital, Liverpool. 